\title{
Autologous GM-CSF-secreting Lethally Irradiated Pancreatic Cancer Vaccine
}

National Cancer Institute

\section{Source}

National Cancer Institute. Autologous GM-CSF-secreting Lethally Irradiated Pancreatic

Cancer Vaccine. NCI Thesaurus. Code C91707.

An irradiated, autologous pancreatic cancer vaccine consisting of patient-specific pancreatic cancer cells genetically modified to secrete the cytokine granulocytemacrophage colony stimulating factor (GM-CSF), with potential immunostimulating and antineoplastic activities. Upon vaccination, GVAX pancreatic cancer vaccine secretes GMCSF. In turn, GM-CSF may stimulate the body's immune system against tumor cells by enhancing the activation of dendritic cells (DCs) and promoting antigen presentation to both B- and T-cells. In addition, GM-CSF promotes antibody-dependent cellular cytotoxicity (ADCC), and increases interleukin-2-mediated lymphokine-activated killer cell function. 